\title{
Ten years after: Enduring questions and celebrating answers about situation tables and CSWB
}

\author{
Norman E. Taylor*
}

In early February 2011, about 25 diverse local professionals sat down together for the first time in a shopping mall community room in Prince Albert, Saskatchewan. Later dubbed "the original gamechangers," they began cautiously that day to develop a new process of collaboration. They engaged with one another in a multi-lens triage intended to bring immediate and urgently needed service connections to individuals and families facing compound risk factors that, while not yet at the incident or even crisis level, could be readily recognized as heading swiftly and inevitably in that direction. Adapted from a similar process underway in Scotland, this marked the official launch of the Prince Albert $\mathrm{Hub}$, an informal innovation in collaborative practice that would inspire well over 100 similar community efforts over the decade to come. The original "hub" label soon yielded to a new name, the Situation Table, more widely accepted in other provinces. Today, it is still recognized under both names and on both sides of the Canada-United States border. I will in this paper refer to it as the Situation Table or, simply, the Table.

I begin by recognizing that from time to time, questions about the Situation Table will continue to be raised, as they would for any high-profile innovation, in various circles, including mainstream media, fringe media, social media, and most importantly, among sector-specific policy, practice, and academia communities. Most often, these discussions are well intentioned, aiming to advance and improve continuing innovation and systemic reform in all aspects of community safety, well-being, and social equity. At times, for reasons unknown to me, some of these discussions have also given rise to misinformed assumptions and false characterizations about what the roles, functions, and practices of the Situation Table actually entail. In this brief commentary, I offer my personal and professional observations as a brief recap of some of the most salient characteristics that have defined the Situation Table from the start-and throughout its multiple adoptions-and which might more accurately position the Table amid broader Community Safety and Well-Being (CSWB) ambitions.
In the interest of full disclosure, I have been involved with this innovation from the very beginning, including in our initial on-site observations in Scotland, and earlier, in authoring the emerging provincial strategy that provided the ideal context for whole-of-system experimentation. I also continue, among my other professional activities, to provide advisory and learning support to assist adopting communities in achieving the all-important fidelity at their Tables, ever mindful of my own decade of intense and productive deliberations with privacy officials across the entire system. All of these efforts have been undertaken across Canada and in the United States, together with my business partners, and with other advisory colleagues, senior policy officials, and front-line practitioners from every sector of the human services.

It is not my purpose in this paper to explain in depth the theory and practice of the Table. Such information is widely available and better addressed in another time and place. Rather, this paper derives from my deep respect and admiration for the originators in Prince Albert, and for all the others who have since invested their time, learning and passion in the mobilization, support, and operations of their own community Tables. As we collectively reach this onedecade milestone, it seems to me important to revisit some of the framing truths, and to dispel some of the most lingering myths, about this innovative practice that was conceived and designed to bring immediate support to those who need it most and to inform and lead us all towards lasting, yet still too elusive, systemic reform.
What's It All About?
The Table is sometimes inaccurately described as a "police program" or a "crime reduction model." It is not, and it was never conceived as such. The original architects of the model took early steps to distinguish the Table as a multi-sector collaboration aimed at achieving immediate and safer outcomes for persons, families, and communities experiencing what they came to define as acutely elevated risk (AER), as viewed across a range of disciplines and their

Correspondence to: Norman E. Taylor, Community Safety Knowledge Alliance, 120 Sonnenschein Way - Main, Saskatoon, SK S7M OW2, Canada. E-mail: ntaylor@cskacanada.ca

To cite: Taylor, N. E. (2021). Ten years after: Enduring questions and celebrating answers about situation tables and CSWB. Journal of Community Safety and Well-Being, 6(1), 35-37. https://doi.org/10.35502/jcswb.185

(C) Author(s) 2021. Open Access. This work is distributed under the Creative Commons BY-NC-ND license. For commercial re-use, please contact sales@sgpublishing.ca. gPUBLISHING Published by SG Publishing Inc. CSKA Official publication of the Community Safety Knowledge Alliance. 
respective risk indicators. At the same time, the Table was recognized as a valuable new source of insights into those places where the system was chronically failing to meet the needs of those it is intended to serve. This is also the same combined thinking that ultimately led to the CSWB language that has since taken on strong roots across Canada, and which gave rise to this Journal.

Criminal involvement is just one among the more than 100 risk factors that may form a basis for introducing a situation to a Table, and it is just one among many bases for the subsequent interventions designed and mobilized to reduce composite risk, and to connect people to immediate and essential supports. That said, it can sometimes be among the more prevalent factors listed in the Risk Tracking Database (RTD). The RTD is a somewhat standardized method used at most Tables for capturing and analyzing the strictly deidentified information about the nature of composite risk presenting, and the respective roles of collaborating partners. Experience has consistently shown, however, that criminality is almost never a single or even primary indicator of acute risk in Table situations. More common are such leading or combining factors as victimization, mental health issues, absent parenting, substance use, inadequate housing, chronic school absence, negative peers or environments, to name a few.

Some media reports have correctly identified that police will bring a proportionately higher number of situations to the Tables, averaging in the range of $60 \%$ to $80 \%$, depending on the community involved. This is due in equal parts to the 24/7 nature of policing and to the high exposure many police officers will regularly have to persons and/or families in varied forms of distress. Others have also noted that the police are highly represented in the risk tracking data as a frequent "assisting agency" in Table interventions. However, these references often fail to note the significant fact that this is very different from being the "lead agency." Typically, police are under-represented as the lead agency in Tabledriven interventions (i.e., often in fewer than $10 \%$ of the interventions). This is a vital distinction in that it reflects the important role of the Table in facilitating responses that remain outside of the criminal justice system. If not for the collaborative triage and response made available by the Table, far too often a criminal justice response would occur simply by default.

Through careful discipline under the widely adopted four-filter progressive conversations used at many Tables, the informal collaborations are designed to yield more effective, more sustainable, more equitable, more supportive, and nonpunitive responses.

Some reports have alleged that the Tables may be used as a basis for detecting and targeting criminal involvement and mounting police action in response. Well-trained Tables and their Chairs will ensure constant vigilance to avoid such situations should they be introduced at the Table. If, upon a brief de-identified introduction to the Table, an immediate police response is indicated (or any other punitive or mandated response, such as an immediate child protection action), the Table will quickly recognize that the situation does not meet the criteria to advance at the Table. In such situations, a unilateral or bilateral response may result, away from and altogether apart from the Table process, and with no further information ever introduced or discussed at the Table.
Table participants must recognize that not all situations can be mitigated by collaborative, risk-based intervention, and in particular, if situations have already advanced beyond AER and are essentially presenting at the "incident," "emergency," "crisis," or "threat" level.

Sadly, there will always be situations in the community that will have already moved too far downstream, beyond the reach of supportive and preventive interventions. In response to such situations, our individual systems are well-equipped to take immediate, decisive, and appropriate action where it is required. In response to such situations-a child in immediate danger, a gun on the kitchen table, a knife in a school locker, an intoxicated person about to freeze on the street-the options are very limited, are typically perceived as more punitive to those involved and, often, are only temporarily and marginally effective as a result. To paraphrase a common sentiment among those responding to and facing such limited options: "If only we got here yesterday, or even last week." Such is the essential ambition of the Table: preventing tragedy wherever it can be achieved, even knowing it will not always be able to do so.

\section{The Case for the Evidence}

Throughout the past decade, there has been considerable discussion about the "evidence-based" nature of the Situation Table. Critics may point out that Tables have not been subjected to the Random Control Trial (RCT) evaluation. Much of this criticism originates from the field of Criminology, where RCT is widely recognized as the gold standard of evidencebased policing (EBP) practice. The early architects and most progressive adopters gave deep consideration to the available range of measures and methods for evaluation, and have taken an early and sustained view that Tables are not particularly conducive to RCT and certain other forms of quantitative evaluation for three primary reasons:

First, the Table has never been a program or a structure, and it is definitely not "a crime prevention program," as discussed above. It is a structured informal conversation at which the evidence-based practices of all Table-active sectors apply at all times, along with all individualized standards of care, conduct, and research excellence. The Table provides a unique opportunity to examine situations through multiple lenses simultaneously, and simply to mobilize every sector that has an immediate-and supportive-contribution to make, with actors always operating within the bounds of their own respective disciplines.

Second, to attempt an RCT on the Table itself, as just one methodological example among many, could risk violating the careful privacy provisions embedded not only in the four-filter process of the Tables, but in the very nature of the complex situations they address. Early discussions with privacy experts consistently pushed back hard against any role in "follow-up study" at or by the Table itself. There are boundless opportunities for evidence-based practice and evaluation in every strand and at every stage of the care path, and each of these paths can and must continue to operate within its own strict disciplines and ethical frameworks. At the same time, it is worth noting there is overwhelming and recurring evidence in the Canadian and global literature, and in the ongoing research that guides each of these separate strands, that consistently confirms, documents, and supports 
the vital importance of interdisciplinary collaboration to improve outcomes. It was an extensive multi-disciplinary study into this evidence that originally gave provincial authorities in Saskatchewan the confidence to embrace their whole-of-government commitment. This body of evidence has continued to grow, through such broad communities as the global Law Enforcement Public Health (LEPH) community, the World Health Organization, international EBP collaboratives, mental health and substance use communities of practice, educators, Indigenous community knowledge, and many more sources, reinforcing similar confidence in every jurisdiction that has since embraced the original concepts behind the Tables.

Third, to make any real attempt at a control group study might be to presume that a selection of situations of AER could be a) recognized in advance; and b) left unattended such that they do not receive the benefit of a collaborative Table response, in order to draw a comparative sample against those situations that do. This was rejected very early as a completely abstract and frankly absurd idea, and it would still be regarded as an irresponsible and unethical proposition by most well-informed Table practitioners.

Ultimately, the decision will always rest with community leaders whether to adopt and/or to sustain the local investment of energies that go into a Situation Table, and hopefully also to gather and make meaningful use of the anonymous risk-tracking data in service of more equitable CSWB outcomes and systemic reform. As such, most Tables across Canada have been subjected to rigorous and continuing forms of evaluation at the local level, usually (and ideally) across multiple dimensions and indicators of health and well-being, derived from the participation of a full range of human service sectors and community representatives. Several such studies have been published or produced as local and provincial or state-level government reports. Others have been published as research studies, using both qualitative and quantitative methods, and ranging from lived experience studies to economic analyses.

\section{A Duty of Care, But Let's First Do No Harm}

Ultimately, keeping in mind that the Table is merely a "conversation" and neither a program nor an institution, the strongest evidence will continue to resonate from the broad range of extant literature on the value of and urgent need for collaboration among sectors and service providers. The most reliable source of "evaluation data" on this collaboration has and continues to be the community of well-qualified professionals from all sectors. Most have consistently expressed the value the Table holds for them in their own work, as an effective and responsible mechanism to achieve better and more frequent collaboration, at the Table and beyond, allowing them to more effectively mobilize and achieve essential connections to service and compassionate support for clients facing composite risk, many of whom have been otherwise and too often failed by the fragmented nature of our complex systems.

Many of these same committed practitioners will tell you that it is never easy to operate differently, as the Table calls for them to do once or twice a week. Institutionalized patterns and siloed cultures can be very confining, and rewards often flow more freely to those who simply reinforce them. Thus, it takes a lot of mutual support at the Table to help one another navigate the careful balance between doing no harm to the privacy of individuals and families and recognizing there is a shared duty of care in complex situations of acutely elevated risk, which if and when they can be seen, must be acted upon.

Would-be critics of the Situation Table might take a page from the compassionate experience of these Table practitioners. If we truly want the health, human services, and criminal justice systems to learn how to function better, to overcome the inequities of systemic racism and classism, and to fill the empty spaces of healing and support left by well-intentioned but fragmented service provision, it may be incumbent on all of us to extend a similar duty of care, and just maybe a bit more due respect, to those very professionals who, for ten years now, have been seeking and acting responsibly on better ways.

If you're among those few who are simply chasing a controversy of your own making, I might recommend you first read through a decade of inquests, death reviews, and similar incident reports available from every health, social, and justice sector. We are all very familiar, of course, with those tragic use-of-force situations that still arise too often in police responses, many of which have resulted from other upstream system failures-to-connect. We are also shocked when we learn of inequitable and dehumanizing treatment in hospitals, clinics, or out on community sidewalks that have led to tragic outcomes in the absence of sufficient supports. And please, don't even get me started on the recurrence of very avoidable tragedies arising from inadequately supported situations of intimate partner violence, domestic violence, sexual, gender, and hate-based violence, and child negligence, exploitation, and abuse.

So common in many of these reviews will be after-thefact discoveries of who did not know what they needed to know in order to make a difference. Even more shocking is how often the discoveries will be about what too many already did know. Those, who were somehow impeded in their ability to reach outside of their own professional scope, and to reach across to the others who also knew, and to responsibly mobilize collective supports to those who desperately needed them. Those, who might have gotten there yesterday, or even last week. Those, who might have taken but who did not take the collective, real time, supportive action necessary to ensure that the failures in our systems might, this time, do no harm.

There hides a story that still deserves to be told.

Meanwhile, after a decade of their real and widespread innovations in CSWB, I invite you to join me in saluting those who continue to change the game, through their courageous efforts and evident successes at Situation Tables, and in a host of other collaborative initiatives across our nations.

\section{CONFLICT OF INTEREST DISCLOSURES}

The author has continuing business interests that include providing advisory services to communities, police services and related human service agencies.

\section{AUTHOR AFFILIATIONS}

* Community Safety Knowledge Alliance, Saskatoon, Saskatchewan, Canada. 